Meta

Journal des traducteurs

Translators' Journal

\title{
Quality Assessment in Conference and Community Interpreting
}

\section{Franz Pöchhacker}

Volume 46, numéro 2, juin 2001

Évaluation : paramètres, méthodes, aspects pédagogiques /

Evaluation: Parameters, Methods, Pedagogical Aspects

URI : https://id.erudit.org/iderudit/003847ar

DOI : https://doi.org/10.7202/003847ar

Aller au sommaire du numéro

Éditeur(s)

Les Presses de l'Université de Montréal

ISSN

0026-0452 (imprimé)

1492-1421 (numérique)

Découvrir la revue

Citer cet article

Pöchhacker, F. (2001). Quality Assessment in Conference and Community Interpreting. Meta, 46(2), 410-425. https://doi.org/10.7202/003847ar

\section{Résumé de l'article}

L'interprétation peut et devrait être placée dans un champ conceptuel qui comprend des sphères d'interaction allant de l'international à l'intrasocial. La bonne qualité du travail de l'interprète doit être garantie dans tous les domaines professionnels. Partant de ces hypothèses, cet article résume le panorama de la recherche actuelle en interprétation ciblée sur les instruments conceptuels et méthodologiques pour évaluer et étudier de façon empirique la qualité d'une prestation. Se fondant sur un compte rendu sélectif des approches d'investigation et des résultats concernant les différentes composantes de la qualité et les types d'interprétation, l'auteur constate qu'il existe une base commune assez solide pour encourager un dialogue enrichissant entre les recherches sur l'évaluation de la qualité réalisées dans les différents domaines de la gamme typologique de l'activité d'interprétation. 


\title{
Quality Assessment in Conference and Community Interpreting
}

\author{
FRANZ PÖCHHACKER \\ University of Vienna, Vienna, Austria
}

\begin{abstract}
RÉSUMÉ
L'interprétation peut et devrait être placée dans un champ conceptuel qui comprend des sphères d'interaction allant de l'international à l'intrasocial. La bonne qualité du travail de l'interprète doit être garantie dans tous les domaines professionnels. Partant de ces hypothèses, cet article résume le panorama de la recherche actuelle en interprétation ciblée sur les instruments conceptuels et méthodologiques pour évaluer et étudier de façon empirique la qualité d'une prestation. Se fondant sur un compte rendu sélectif des approches d'investigation et des résultats concernant les différentes composantes de la qualité et les types d'interprétation, l'auteur constate qu'il existe une base commune assez solide pour encourager un dialogue enrichissant entre les recherches sur l'évaluation de la qualité réalisées dans les différents domaines de la gamme typologique de l'activité d'interprétation.
\end{abstract}

\section{ABSTRACT}

On the assumption that interpreting can and should be viewed within a conceptual spectrum from international to intra-social spheres of interaction, and that high standards of quality need to be ensured in any of its professional domains, the paper surveys the state of the art in interpreting studies in search of conceptual and methodological tools for the empirical study and assessment of quality. Based on a selective review of research approaches and findings for various aspects of quality and types of interpreting, it is argued that there is enough common ground to hope for some cross-fertilization between research on quality assessment in different areas along the typological spectrum of interpreting activity.

\section{MOTS-CLÉS/KEYWORDS}

quality assessment, conference interpreting, community interpreting, empirical studies, quality standards

\section{INTRODUCTION}

In the closing session of the First BABELEA Conference on Community Interpreting, held in Vienna in early November 1999, Rocco Tanzilli, the head of the European Commission's Joint Interpreting and Conference Service, addressed the concerns of community interpreting professionals and researchers by demanding high quality standards for any type of interpreting activity, in short: "quality across the board." Since quality assurance implies some form of quality assessment, and the latter in turn requires a sound conceptual and methodological foundation, the present paper is intended as a survey of the state of the art in interpreting studies with regard to the issue of quality and its assessment.

Preparing the ground for this undertaking, I will first discuss the notion of 'quality' as well as the criteria and standards by which quality is to be assessed. The main 
part of this paper will then be devoted to a review of research approaches and findings for various aspects of quality and types of interpreting. Rather than give a comprehensive review of all and any quality-related research, the scope of the paper is limited to an overview of various methodological approaches with reference to some exemplary studies. On that basis, I will attempt to show whether and to what extent quality-related research on interpreting might benefit from cross-typological links so as to both strengthen the common ground of research on interpreting quality and highlight the specific quality features of particular domains of the profession.

\section{CONCEPTUAL ISSUES}

On the assumption, shared by a growing number of scholars in the interpreting studies community, that there is something to gain by taking a comprehensive, unifying view on interpreting before focusing on a particular domain for specific investigations, I will define 'interpreting' as a conceptual spectrum of different (proto)types of activity. Notwithstanding the use of established terms in the title and the rest of this paper, it is important to stress that 'conference interpreting' and 'community interpreting' are understood not in terms of a dichotomy but as different areas along a spectrum which ranges from interpreting in an international sphere of interaction, among representatives of entities based in different 'national' or multi-national environments, to interpreting within an institution of a particular society or social community, between individuals and representatives of that institution.

A bird's-eye view of the interpreting profession today-and of research on qualityrelated issues-yields a very uneven picture. While a considerable amount of work has been done on quality in conference or simultaneous interpreting, interpreting quality in intra-social settings has received only sporadic scholarly attention. I will therefore take advantage mainly of the literature on quality in conference interpreting (e.g. Gile 1991, Moser-Mercer 1996, Shlesinger 1997, Kahane 2000) for a sketch of the basic assumptions and insights regarding assessment perspectives and quality criteria which can be applied along the entire spectrum of interpreting activity.

\subsection{Perspectives on Quality}

When empirical research on quality criteria in conference interpreting came under way in the late 1980s, a distinction was made between quality assessment from the perspective of interpreters themselves as opposed to quality as 'viewed' by the listeners ('users'). As reviewed by Kurz (in this volume), the study of user expectations developed into a very productive line of research which has pointed to some variability in the quality expectations of different user groups as well as to discrepancies in the attitudes of participants in the role of listener (target-text receiver) and speaker (source-text producer).

Gile (1991) modeled the "communication configuration" as including not only the interpreter and the users in the roles of "Sender" and "Receiver" but also the position of the "Client" or employer who commissions and pays for the interpreter's services. Other authors have added to the range of potential assessors of interpreting quality: the interpreter's colleague(s), associates or representatives of the client or users as well as persons with an analytical or research interest (cf. Pöchhacker 1994: 
123, Moser-Mercer 1996: 46). The last-mentioned category is used by Viezzi (1996: 12) for a more general distinction between the perspectives of the interpreters and the users (listeners, speakers) as discussed above, and the perspective of the 'external observer' who takes a research approach to interpreting and is interested in measuring 'objective' features of the textual product. Since it is equally possible, of course, to try and 'measure' subjective attitudes and judgements, it may be helpful to try and model the relationships between the various positions and perspectives as depicted in Figure 1:

FIGURE 1

Perspectives on quality in interpreting

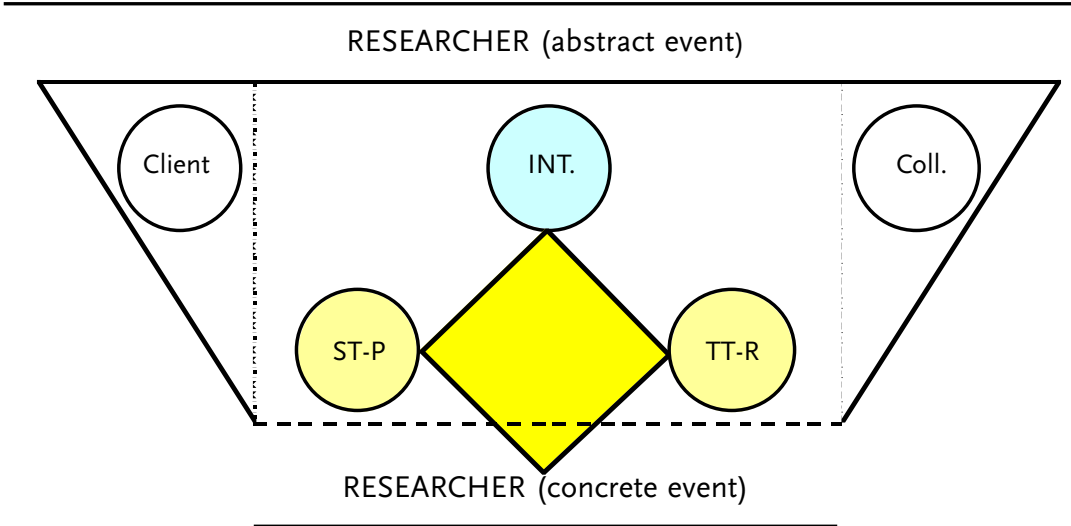

$(\checkmark=$ communicative event, ST-P $=$ source-text producer, TT-R $=$ target-text receiver $)$

The core constellation of interactants directly involved in the communicative event of text production/reception is depicted (within a rectancle) as the triad made up of the interpreter (INT.), the speaker (ST-P) and the listener (TT-R). The roles of Client (employer) and Colleague (fellow interpreter/team member) appear as additional positions from which the quality of interpreting can be assessed.

Beyond summarizing the multiple perspectives on quality, Figure 1 is meant to highlight two important analytical distinctions underlying the study of quality in interpreting. Firstly, the 'external observer' may investigate the various actors' attitudes, needs and views ("norms') either "off-site," with regard to an abstract (hypothetical or previously experienced) interpreting event or with reference to a concrete communicative event in a given communication situation. The latter implies a more direct access by the researcher to the communicative event, which is represented in Figure 1 by the broken rather than continuous line separating the researcher from the constellation of interactants and also by the 'external reality' of (at least some part of) the textual product. Secondly, therefore, research on quality in a concrete interpreting event may focus either on the recordable product or on the overall process of communicative interaction. These two perspectives-product-orientation and interaction-orientation-are of fundamental importance also to the key issues of quality standards and assessment criteria. 


\subsection{Quality Standards and Criteria}

Despite the fact that quality in interpreting may be assessed differently from various subjective perspectives and is thus essentially 'in the eye of the beholder', there is considerable agreement in the literature on a number of criteria which come into play when assessing the quality of interpreting. While the terminology may vary from one author or text to the other, concepts such as accuracy, clarity or fidelity are invariably deemed essential. These core criteria of interpreting quality are associated with the product-oriented perspective and focus primarily on the interpretation or target-text as "a 'faithful' image" (Gile 1991: 198) or "exact and faithful reproduction" (Jones 1998: 5) of the original discourse. The notion of clarity (or linguistic acceptability, stylistic correctness, etc.), on the other hand, relates to a second aspect of quality, which could be described more generally as 'listener orientation' or targettext comprehensibility.

Beyond this two-pronged textual perspective, i.e., "intertextual" and "intratextual" analysis (Shlesinger 1997: 128), the interpreter is essentially expected to "represent fully" the original speaker and his/her interests and intentions (cf. Gile 1991: 198), hence the criterion of 'equivalent effect' as formulated by Déjean Le Féal (1990: 155) for simultaneous interpreting. Finally, the focus of quality assessment may be neither on the source text nor on listeners' comprehension or speakers' intentions but on the process of communicative interaction as such. From this perspective, which foregrounds the '(inter)activity' of interpreting rather than its nature as a 'text-processing task' (cf. Wadensjö 1998: 21ff), quality essentially means “successful communication” among the interacting parties in a particular context of interaction, as judged from the various (subjective) perspectives in and on the communicative event (cf. Gile 1991: $193 \mathrm{ff}$ ) and/or as analyzed more intersubjectively from the position of an observer.

As indicated above, the various sets of criteria underlying quality assessment in interpreting pertain to different aspects or even conceptions of the interpreter's task, ranging from text processing to communicative action for a certain purpose and effect and, most generally, to the systemic function of facilitating communicative interaction. As depicted in Figure 2, the model of quality standards ranging from a lexico-semantic core to a socio-pragmatic sphere of interaction can be viewed as reflecting the fundamental duality of interpreting as a service to enable communication and as a text-production activitiy (cf. Viezzi 1996: 40).

FIGURE 2

Quality standards for the product and service of interpreting

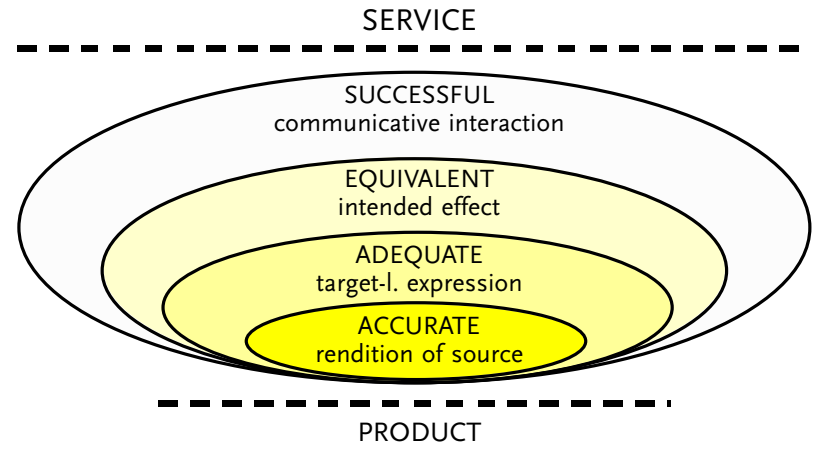


Given the multiple perspectives and dimensions modeled above, there is a broad range of methodological approaches to the study of quality in interpreting. The following section will give an overview of quality-related research methods and topics with reference to interpreting in both conference and community settings. In line with the basic idea of this paper, reference will be made to research across the entire spectrum of interpreting activity. Nevertheless, since quality in conference interpreting has been reviewed in other publications (e.g. Viezzi 1996, Shlesinger 1997, Kahane 2000), most of the attention and space will be devoted to the presentation of research on quality in community-based domains.

\section{METHODOLOGICAL APPROACHES}

Empirical studies on quality in interpreting have been carried out along various methodological lines, the most popular and productive of which has been the survey.

\subsection{Survey Research}

Survey research on the basis of questionnaires or structured interviews targeting one or more positions in the constellation of communicative interaction (cf. Fig. 1) has been conducted both from the generic perspective, often with reference to the interpreter's task as such, and with reference to concrete interpreting events.

\section{Interpreters}

If interpreting is viewed in its duality as a service, rendered by an individual (or group, team, etc.), and as a textual product, the issue of quality can be formulated as "What makes a good interpreter?" and "What makes a good interpretation?" These generic questions have been asked in surveys addressed to interpreters and/or users of interpreting since the 1980s. In Australia, Hearn (1981) and co-workers surveyed a total of 65 interpreters in an evaluation of two regional interpreting services. One of the 65 question items covered in personal interviews focused on the qualifications of a 'good interpreter' and yielded such criteria as knowledge of both languages and of the migrant culture, objectivity, socio-communicative skills, reliability, responsibility, honesty, politeness and humility (Hearn et al. 1981: 61). The interpreters were also asked about their perception of attitudes and expectations prevailing among their professional clients, particularly regarding the definition and acceptance of the interpreter's role and task. A separate question addressed the issue of 'cultural mediation', which has been of prime concern to those reflecting on the community interpreter's role and was also addressed in the survey of Mesa (1997) described further down.

In her pilot study among conference interpreters, Bühler (1986) had 47 conference interpreters rate the relative importance of criteria like endurance, poise, pleasant appearance, reliability and ability to work in a team, in the evaluation of interpreters. At around the same time, 39 members of the German region of AIIC were interviewed about issues of their profession, and a long list of prerequisites emerged for a 'good interpreter' and team member, ranging from linguistic and general knowledge to voice quality, and from good health and endurance to psychosocial qualities such as appearance, poise, politeness and flexibility (cf. Feldweg 1996: 326-378). 


\section{Users}

Prompted by Bühler's (1986) attempt to generalize from her findings to the quality needs and expectations of users (listeners), questionnaire-based user expectation surveys were introduced by Kurz and turned into a highly productive line of research (cf. Kurz, in this volume). While some of the user surveys narrowed the focus to Bühler's product-related ("linguistic") criteria, particularly for simultaneous interpretation, others broadened it to include aspects of the interpreter's role and the specifics of consecutive interpretation and particular meeting types (cf. Kopczynski 1994, Marrone 1993, Vuorikoski 1993). A significant distinction was made by Kopczynski (1994) between the preferences of users as 'speakers' as opposed to 'listeners' in a conference setting. While the former would tolerate a greater extent of intervention by the interpreter, the latter showed a stronger preference for the 'ghost role' of the interpreter and favored a close rendition of the speaker's words and even mistakes (cf. Kopczynski (1994: 195ff).

In community interpreting, where bilateral short consecutive ('liaison') interpreting of dialogue is the most common mode by far, the distinction between the two user roles is of a different nature. Whereas the primary interacting parties will usually take alternating turns at speaking and listening, they are essentially different in their status as 'representatives' as opposed to 'clients' of an institution or public service. It is thus common to refer to 'service providers' or 'professionals' on the one hand and 'non-(majority-language)-speaking clients' on the other. Both of these 'user perspectives' - as well as that of the interpreters-were investigated by Mesa (1997), who administered questionnaires to 66 clients (in 11 different languages) and 288 health care workers from 30 different institutions in the Montréal region. Whereas the former were asked about their perception of the quality of interpreting services received (see below), the latter were asked to rate the importance of over 30 interpreter qualities and behaviors on a three-point scale (très - assez - peu important). In the survey of service provider expectations, the items which received the highest ratings ('very important') from most of the respondents included 'fully understands client's language' (96\%), 'ensures confidentiality' (95\%), 'points out client's lack of understanding' (92\%), 'refrains from judgement' (91\%) and 'translates faithfully' $(90 \%)$. Strikingly, however, the expectation that the 'cultural interpreter' generally 'explains cultural values' ranked low among service providers' expectations (61\% 'very important'), and even fewer respondents (47\%) considered it very important to receive cultural explanations from the interpreter after the mediated exchange.

Service providers' expectations of what interpreters ought to do in various institutional settings were also investigated in two questionnaire-based surveys conducted in Vienna. Pöchhacker (2000) collected responses from 629 health care and social workers on interpreter qualifications and role definitions. Out of ten criteria, such as linguistic and cultural competence, general education, specialized knowledge, training in interpreting, strictly neutral behavior, and discreteness and confidentiality, only the latter two were rated 'very important' (on a three-point scale) by a majority of respondents. Nevertheless, user expectations among these service providers were highly demanding. More than two-thirds of respondents saw such editorializing functions as simplifying and explaining provider utterances and summarizing of client utterances as part of the interpreter's task, and $62 \%$ each also expected interpreters to 
explain cultural references and meanings and to formulate autonomous utterances when asked to do so by the provider. An analysis of the data by professional groups (doctors, nurses, therapists, social workers) yielded a number of significant differences. Thus, nurses tended to construe the interpreter's role much more broadly than doctors, whereas social workers showed much greater acceptance for the interpreter's role as a cultural mediator. As in the study by Mesa (1997), hospital interpreters themselves felt much more strongly than health care personnel that providing cultural explanations was part of their job (83\% vs. 59\%).

Kadric (2000) used a similar questionnaire-based approach to ascertain user expectations regarding the qualifications and task definition of courtroom interpreters. Her target population consisted of some 200 local court judges in Vienna. As regards qualifications, the 133 respondents rated 'interpreting skills' and, in second place, 'linguistic and cultural competence' more highly than 'basic legal knowledge' and 'knowledge of court organization and procedure'. Asked about their definition of the interpreter's task, the judges turned out to be less restrictive than one might expect from the literature (cf. Morris 1995), showing considerable acceptance of summarizing (46\%), simplifying the judge's utterances (63\%), explaining legal language (72\%) and even formulating routine questions and admonitions on behalf of the judge $(72 \%)$. As many as $85 \%$ of respondents expected the interpreter to explain cultural references for the court.

Since the local court judges surveyed by Kadric (2000) are also responsible for hiring interpreters when needed, the study is unique in that it also addresses the perspective of the 'client' in the broader sense of the term as described below.

\section{Clients}

In the literature on community interpreting the role of 'client' is usually taken to refer to the individual client of the institution or public service, and thus to the interpreter's 'individual' as opposed to 'professional client' in the communicative exchange. In a more general sense, however, the interpreter's client must also be seen as the individual or institution that commissions-and pays for-his or her services (cf. Fig. 1). Notwithstanding the pivotal role of the client-in the sense of 'employer'-in the constellation of interpreting as a professional service, the quality expectations associated with this position have received very little attention. The study by Kadric (2000) on courtroom interpreting points to the specifics of this perspective on quality by investigating 're-hiring criteria', such as 'smooth facilitation of communication', and eliciting additional concerns such as costs and fees (cf. Kadric 2000: 126-136).

In the area of conference interpreting, a major survey on quality in interpreting from the employer perspective has been undertaken by the Joint Interpreting and Conference Service of the European Commission, the world's largest client of interpreting services. Not surprisingly, it adds cost and management considerations to the list of quality-related concerns and thus addresses the dimension of the service as well as that of individual interpreters and their work (cf. Kahane 2000).

\section{Case-based Surveys}

Apart from surveys designed to elicit normative views and expectations regarding a more or less abstract notion of interpreting and interpreters, survey research has also 
been carried out with reference to quality in concrete conference interpreting events (cf. Kurz, in this volume). For community interpreting settings, a case-based cumulative survey method was developed and applied by a Canadian cultural interpreter service (Garber and Mauffette-Leenders 1997). Feedback from 34 non-Englishspeaking clients in three language groups (Vietnamese, Polish, Portuguese) was obtained by way of translated questionnaires which were given out by 17 interpreters in a total of 72 assignments. Among other things, clients were asked to rate comprehensibility on a six-point scale and to state their perception of the quality of interpreting with reference to criteria such as accuracy and impartiality. A more elaborate evaluation form was used for service providers in the same encounters, thus implementing a quality assurance system covering both individual client and service provider perspectives. The survey by Mesa (1997) already mentioned above made a similar distinction between the individual client and the service provider perspective. Whereas the 66 clients (of eleven different language backgrounds) were asked mainly to express their agreement (or disagreement) with ten evaluative statements on features of the interpreter's performance, service providers were asked to complement their generic user expectation ratings by stating to what extent ('yes'- 'more or less' - 'no') they had seen the members of the interpreting service under study actually fulfilling those expectations.

If user expectations and the perception and assessment of quality in actual encounters may be two different things, it is yet another to try and assess the 'reality' underlying subjective judgements on a particular interpreting product (cf. also Gile 1990: 68). An interesting attempt at doing so is the (experimental) study by Strong and Fritsch Rudser (1992) on the subjective assessment of sign language interpreters. Using a simple survey instrument (evaluation form) with items like the interpreter's linguistic ability as well as the overall quality ('like'- 'dislike') and comprehensibility of the interpretation, six deaf and six hearing raters assessed passages from interpretations (into sign language and into English, respectively) by 25 interpreters of a diverse level of skills. Inter-rater reliability was found to be quite high, though not as high as inter-rater agreement for the propositional accuracy scores used as a measure of objective evaluation. Strong and Fritsch Rudser (1992: 11) take their findings to suggest that "while subjective ratings provide an interesting and useful dimension of interpreter assessment, they should not replace a sound objective measure."

This example points to the need for analyzing the 'reality' underlying evaluative judgements so as to overcome the methodological limitations of interactive observational research, particularly the risk of a systematic personal or contextual bias in the responses (cf. Gile 1998: 74). Since that 'reality' is primarily the interpreter's output or target text (in a broadly semiotic sense), non-reactive observational research has focused mostly on the analysis and evaluation of textual-linguistic data. While this kind of approach could be taken to imply the use of authentic data as they occur 'in the field', textual-linguistic analyses have been developed and applied mainly in experimental studies, with criteria like accuracy and adequacy (cf. Fig. 2) serving as dependent variables in the research design. 


\subsection{Experimentation}

\section{Measures of performance}

Experimental studies on (simultaneous) interpreting since the 1960s have shown a keen interest in the impact of various input parameters (e.g. speed, noise) on the interpreter's 'performance'. While experiments did not explicitly address the issue of quality as such, looking at interpreters and at 'how well they do under particular circumstances' is certainly linked up with quality assessment or at least a particular aspect of it. In fact, many experiments were designed in such a way as to measure the presumably essential parameter of 'accuracy'. Error counts (e.g. Barik 1971), scores of 'informativeness' as well as 'comprehensibility' (Gerver 1971), various types of propositional-or verbal-accuracy scores (e.g. Mackintosh 1983, Tommola and Lindholm 1995, Lee 1999a) and even acoustic synchronicity patterns (Lee 1999b, Yagi 1999) have all been used, more or less confidently, as objective measures of interpreting performance in experimental settings. Only some authors explicitly acknowledge that their 'scoreable textual parameters' cover only a certain 'aspect of quality', if they reflect 'quality' at all. Mackintosh (1983: 15), for instance, who used a complex semantic scoring system and calculated inter-rater reliability among her three judges, clearly stated: "In any exercise designed to permit a qualitative assessment of interpretation products, it would be necessary to refine the scoring system." A similar acknowledgement of the limitations of his error coding system is formulated by Barik (1971: 207): "Nor is the system intended to reflect except in a very gross way on the adequacy or 'quality' of an interpretation since other critical factors such as delivery characteristics: voice intonation, appropriateness of pausing, etc., are not taken into consideration." This problem is still unresolved, as stated recently by Gile: "[...] while there may be inter-subjective agreement on large differences in interpretation quality, at more subtle levels, the interpreting research community is still groping in the dark and has not found a valid, sensitive and reliable metric to measure interpreting performance" (Gile, in Niska 1999: 120).

One way of overcoming the methodological limitations of 'traditional' experimenting is the use of (some feature of) quality not as the dependent but as the experimental input variable.

\section{Quality as Input Variable}

Unlike the measurement of accuracy-related aspects of quality referred to above, studies involving the manipulation of output quality features in the experimental design have tended to focus on the dimension of target text adequacy for a particular audience. This approach to experimentation in interpreting was pioneered by BerkSeligson (1988) in her research on court interpreting. She presented a group of mock jurors with two stylistically different versions of a court interpreter's rendering of witness testimony and was able to show that variations in register (politeness) will significantly affect the way in which listeners perceive and judge the original speaker's credibility, in this case as a witness.

In the area of simultaneous conference interpreting, two innovative studies focused on precisely the feature that was found to be relatively unimportant in a number of user expectation studies. Shlesinger (1994) presented listeners with two versions of a target text, one delivered with what she analyzed as interpretational 
intonation', the other read with 'standard' rhythm, stress and prosodic patterns. In a comprehension and recall test administered to her two groups of subjects, the group which had listened to the read version with standard intonation gave $20 \%$ more correct answers than the group listening to the interpretation. In another experiment on the impact of intonation, Collados Ais (1998) produced three intonationally and/or informationally different interpreted versions of a (simulated) conference speech and asked experienced users of simultaneous interpretation to judge the quality of the interpretation with the help of a questionnaire. Even though the same subjects had confirmed the relative insignificance of nonverbal features in a prior user expectation survey, their direct assessment of the quality of the (simulated) interpretation and of the interpreter demonstrated a significant impact of the monotonous intonation in the experimental input material.

Each of the studies mentioned above touched on 'quality' in terms of the cognitive or pragmatic effect of the interpretation on the listeners, thus addressing the criterion of 'equivalent effect' as formulated by Déjean Le Féal (1990: 155). In methodological terms, these experiments also share the use of simulation as a key feature in their research design and thus manage to overcome some of the limitations of laboratory experiments in which, by definition, most of the variables of an authentic communicative setting remain out of view and in which the absence of a user or client invariably leaves the dangling question of 'quality (adequacy) for whom?'

Whereas such effect-oriented studies can do without the analysis of textuallinguistic data, performance-oriented experimentation has traditionally been associated with the processing of recordings and transcripts (often called 'protocols') of the interpreter's verbal output. In rather general terms, such analyses of experimentally generated textual corpora could be referred to as 'corpus-based observation'. For the present discussion, however, a distinction will be made between such 'secondary observation' (analysis) of data from a controlled experimental setting and observational research in the original sense of working with 'naturally occurring' data in the field. Working with authentic corpora will therefore be discussed here as yet another methodological approach to the study of quality in interpreting.

\subsection{Corpus-based observation}

In comparison with the volume of work done on the basis of surveys and experiments, the literature on interpreting quality contains only few corpus-based observational studies. Cokely (1992), for instance, analyzed "interpreter miscues" in a corpus of ten authentic sign language interpretations in a conference setting, Pöchhacker (1994) described quality-related features of the text surface such as interference, hesitation, slips and shifts, as well as problems of coherence in five pairs of original speeches and interpretations, and Kalina (1998) lists 'product analysis' on authentic as well as experimental corpora as the methodological basis of a dozen empirical studies, including research on issues like intonation, interference, errors and selfcorrections.

As evident from the above examples, findings from the analysis of an authentic corpus of textual data are subject to the same kind of limitation as the experimental studies discussed above, i.e., the researcher will gain a view on only one set of features or dimension of quality rather than come to an assessment of quality as such. 
The use of transcripts, to begin with, obviously truncates and distorts the semiotically complex textual product under study. Moreover, at least in the area of conference interpreting, there has been a strong bias in favor of discrete and quantifiable textual features, such as errors, omissions, etc, with little or no regard to complex psychocommunicative relationships and effects.

In the literature on community interpreting, there are very few examples of quantitative analysis of textual corpora (e.g. Ebden et al. 1988). Rather, the subjectnot necessarily of quality - has been dealt with mainly on a qualitative basis, in particular with the use of discourse analytical methods (e.g. Rehbein 1985, Roy 1993, Mason 1999). The application of these research methods specifically to the issue of quality has entered the debate only recently, and there is a distinct awareness that observational studies based on authentic textual corpora alone will be insufficient to the task of evaluating interpreting quality in concrete communicative interactions.

\subsection{Case study}

On the assumption that quality is a multidimensional socio-psychological as well as textual phenomenon within a specific institutional and situational context of interaction, the observational study of quality is arguably best served by methods which allow the researcher to collect a maximum of information on a single case. This concept of case study (cf. Robson 1993: 5), which naturally lends itself to the combination of various observational techniques, has not been very common in interpreting reseach to date.

For research on interpreting quality, case-study design would suggest the combination of corpus-based observation, survey research (interviews), participant observation and documentary analysis so as to ensure a holistic view on quality also at the levels of intended effect and successful interaction, and there have been a few initiatives in which several or all of these methodological approaches are explicitly taken. Gile (1990), for instance, used a questionnaire and reported on his impressions of textual output quality but did not engage in systematic corpus analysis or discuss his approach as a participant observer. Similarly, Marrone (1993) used a questionnaire but did not consider corpus analysis. Since he himself was involved in the case in the role of (consecutive) interpreter, he did install an observer "to 'monitor' events in the light of the questionnaire's parameters" (Marrone 1993: 36) but did not report on any data from that source. Pöchhacker (1994), in his conference case study, used corpus-based data analysis, participant observer notes and documentary analysis but failed to gain sufficient access to conference participants with his user assesment survey. The most successful example of the use of case study research in interpreting is probably the work of Wadensjö (1998), who recorded and analyzed a large corpus of authentic discourse, participated in the interpreted events as an observer, and conducted post-interaction interviews. Given her decidedly descriptive orientation, Wadensjö (1998) largely avoids discussing her data in terms of quality. She does however discuss the prospects of applying her methodological approach to "the whole issue of evaluating (the degree of) interpreters' professional skill.” (Wadensjö 1998: 286) 


\section{4. “QUALITY ACROSS THE BOARD”?}

Against the background of the conceptual dimensions and methodological approaches reviewed in this paper, the issue of quality and how to assess it stands out as a particularly complex research problem. Those who would evaluate quality in interpreting 'across the board' are faced with the fact that interpreting is not a single invariant phenomenon but a (more or less professionalized) activity which takes different forms in different contexts. Therefore, the concept of quality cannot be pinned down to some linguistic substrate but must be viewed also at the level of its communicative effect and impact on the interaction within particular situational and institutional constraints. In the words of Wadensjö (1998: 287): "In practice, there are no absolute and unambiguous criteria for defining a mode of interpreting which would be 'good' across the board. Different activity-types with different goal structures, as well as the different concerns, needs, desires and commitments of primary parties, imply various demands on the interpreters."

Notwithstanding this diversity in the nature of the subject and of the issue under study, researchers focusing on quality assessment in conference and/or community interpreting share a lot of common ground with respect to basic definitions, questions asked, methods used, and problems encountered.

\subsection{Common Ground}

There is agreement in the literature across the typological spectrum that interpreting, conceived of as the task of mediating communication between interactants of different linguistic and cultural background, is, first and foremost, a service designed to fulfill a need. In providing this service, the interpreter essentially supplies a textual product which provides access to the original speaker's message in such a way as to make it meaningful and effective within the socio-cultural space of the addressee. Hence the question, in both conference and community interpreting research, to what extent the interpreter is or should be seen — and expected to act-as a cultural mediator, and what kind of interpreting output will best ensure accurate and communicatively adequate access to what the speaker intended to convey.

Given the multiple perspectives and positions in the constellation of mediated interaction, these questions can be asked more specifically from different angles, such as the normative views and expectations of users of the service and product, the interpreters' own definition of their task, qualifications and standards of performance, the professional client's satisfaction with the service provided, etc. Answers to these questions have been sought in the areas of conference and community interpreting with a similar set of research methods, in particular by the use of questionnaire-based surveys. As regards features of the textual product, both corpus-based observation of interpreting in the field and experimentation as well as simulation have been used, to different extents, in studying quality in community and conference settings. In both domains, there is also some recognition of the methodological merit of in-depth case studies combining interactive data collection for the more service-related assessment criteria with textual (discourse) data analysis for productrelated aspects.

It is true, of course, that the 'common ground' in quality-oriented studies of conference and community interpreting also extends to the methodological problems 
facing the researcher: the difficulty of obtaining a sufficient number of responses to surveys among users, the obtrusiveness of interactive data collection for studying a phenomenon that is often expected to be 'invisible' in the client's communicative event, the problem of contextual bias when abstract expectations are studied within concrete interpreted events, the delicate issue of observing and evaluating the work of (fellow) professionals, limited access to professional subjects for experimental or simulation studies, and the lack of a single product parameter for use as a reliable indicator of quality, all stand in the way of empirical research on assessment models and their application. Nevertheless, it should not seem excessively optimistic to believe that all this common conceptual and methodological ground holds considerable potential for the future of research on quality in interpreting.

\subsection{Prospects}

Since the issue of quality in interpreting as a professional service is here to stay, one can safely expect a steady output of research on this topic, particularly in community-based domains which are currently undergoing professionalization. Provided that researchers take an active interest in work on quality beyond their typological specialty, one could hope for a mutually enriching exchange on research questions, conceptual models and methodological approaches. Among the potential or even actual cases of converging interest one could cite the recent concern in conference interpreting research with the impact of specific institutional constraints (cf. Marzocchi 1998), which has long been a major topic in the study of communitybased interpreting. Similarly, the issue of the interpreter's role as a cultural mediator (Kopczy?ski 1994), particularly in consecutive interpreting (cf. Marrone 1993), is one for which conference interpreting researchers might look toward the communitybased domain for existing models and findings. Kahane's (2000) recent appeal to take a greater interest in situational specifics and "broaden the field by moving from purely linguistic issues to pragmatic, communication issues" is a case in point.

Those focusing on community interpreting, on the other hand, can benefit from techniques for the quantitative linguistic analysis of textual data (e.g. Cambridge 1997) and could apply insights from simultaneous interpreting research to the much-neglected study of whispered interpreting in community settings. In areas of considerable thematic overlap, such as the last-mentioned case of 'whispering', it may prove fruitful to design comparative research projects which bring out both the common ground and the typological specifics of interpreting in various domains. One might, for instance, investigate and compare the dynamics and effects of the consecutive interpretation of dialogues in various settings or the users' expectations of the interpreter's role and requisite qualifications. Would a medical doctor and researcher have the same quality criteria and expectations for interpreters and interpreting at a medical congress and in interviews with patients who speak a different language? Whatever answer one may expect, I would contend that questions such as these should at least be asked and subjected to empirical study.

As evident from the overview presented in this paper, there is a range of conceptual tools and methods which can be used to broaden and refine research approaches to the issue of quality in interpreting. It should have become equally clear that studying quality essentially means doing so from different angles and perspectives, taking 
into account both the product and the service aspects of the activity of interpreting. Multi-perspective surveys as carried out by Mesa (1997), and multi-method approaches in general (e.g. Vuorikoski 1993) should therefore prove vital to the study of quality on either side of the typological spectrum.

\section{CONCLUSION}

The point of departure for the present review paper was the professional aspiration to 'quality across the board'. Hence the idea of surveying the state of the art in interpreting studies in search of conceptual and methodological tools for the empirical study and assessment of quality across the typological spectrum from international (conference) to intra-social (community) interpreting. By taking a broader view on interpreting types, quality aspects and assessment methods, this paper aims to establish the common ground shared by those studying quality in interpreting. To the extent that it succeeds in doing so, it may, hopefully, motivate researchers to look beyond the typological and methodological horizons of their particular specialty and consider enriching their work by learning from that of colleagues in other domains of interpreting.

\section{REFERENCES}

Barik, H. C. (1971): "A Description of Various Types of Omissions, Additions and Errors of Translation Encountered in Simultaneous Interpretation," Meta, 16-4, pp. 199-210.

Berk-Seligson, S. (1988): "The Impact of Politeness in Witness Testimony: the Influence of the Court Interpreter," Multilingua, 7-4, pp. 411-439.

BüHLER, H. (1986): "Linguistic (Semantic) and Extra-linguistic (Pragmatic) Criteria for the Evaluation of Conference Interpretation and Interpreters," Multilingua, 5-4, pp. 231-235.

CAMBRidge, J. (1997): Information Exchange in Bilingual Medical Interviews, dissertation, University of Manchester.

Cokely, D. (1992): Interpretation: A Sociolinguistic Model, Burtonsville, Linstok Press.

Collados Ais, Á. (1998): La evaluación de la calidad en interpretación simultánea. La importancia de la comunicación no verbal, Granada, Editorial Comares.

Déjean Le Féal, Karla (1990): "Some Thoughts on the Evaluation of Simultaneous Interpretation," Interpreting-Yesterday, Today, and Tomorrow (D. and M. Bowen, eds), Binghamton NY, SUNY, pp. 154-160.

Ebden, P., A. Bhatt, O. J. Carey and B. Harrison (1988): “The bilingual consultation," The Lancet, February 13, 1988 [8581], p. 347.

Feldweg, E. (1996): Der Konferenzdolmetscher im internationalen Kommunikationsprozeß, Heidelberg, Julius Groos.

Garber, N. and L. A. Mauffette-Leenders (1997): "Obtaining Feedback from Non-English Speakers," The Critical Link: Interpreters in the Community (S.E. CARR, R. RoBerts, A. Dufour and D. Steyn, eds), Amsterdam and Philadelphia, John Benjamins, pp. 131-143.

Gerver, D. (1971): Aspects of Simultaneous Interpretation and Human Information Processing, thesis, Oxford University.

GiLe, D. (1990): "L'évaluation de la qualité de l'interprétation par les délégués: une étude de cas," The Interpreters' Newsletter, 3, pp. 66-71.

- (1991): "A Communication-Oriented Analysis of Quality in Nonliterary Translation and Interpretation," Translation: Theory and Practice. Tension and Interdependence (M. L. LARson, ed.), Binghamton NY, SUNY, pp. 188-200.

_ (1998): "Observational Studies and Experimental Studies in the Investigation of Conference Interpreting," Target, 10-1, pp. 69-93. 
Hearn, J. (1981): The Unrecognized Professionals, Melbourne, Education Research and Development Committee.

—, T. Chesher and S. Holmes (1981): "An Evaluation of Interpreter Programmes in Relation to the Needs of a Polyethnic Society and the Implications for Education" [Project notes, questionnaire, and summarized responses], Ms.

Jones, R. (1998): Conference Interpreting Explained, Manchester, St. Jerome Publishing.

KADRIC, M. (2000): Dolmetschen bei Gericht. Eine interdisziplinäre Untersuchung unter besonderer Berücksichtigung der Lage in Österreich, Dissertation, Universität Wien.

KaHANE, E. (2000): “Thoughts on the Quality of Interpretation," <http://www.aiic.net/ViewPage. $\mathrm{cfm} /$ page 197.htm $>$ (13.05.2000).

Kalina, S. (1998): Strategische Prozesse beim Dolmetschen, Tübingen, Gunter Narr.

Kopczynski, A. (1994): "Quality in Conference Interpreting: Some Pragmatic Problems," Translation Studies-An Interdiscipline (M. SNell-Hornby, F. PöchHacker and K. Kainde, eds), Amsterdam and Philadelphia, John Benjamins, pp. 189-198.

Lee, Tae-Hyung (1999a): "Speech Proportion and Accuracy in Simultaneous Interpretation from English into Korean," Meta, 44-2, pp. 260-267.

- (1999b): "Simultaneous Listening and Speaking in English into Korean Simultaneous Interpretation," Meta, 44-4, pp. 560-572.

Mackintosh, J. (1983): Relay Interpretation: An Exploratory Study, thesis, University of London.

Marrone, S. (1993): “Quality: A Shared Objective," The Interpreters' Newsletter, 5, pp. 35-41.

Marzocchi, C. (1998): "The Case for an Institution-Specific Component in Interpreting Research," The Interpreters' Newsletter, 8, pp. 51-74.

Mason, I., ed. (1999): The Translator, 5-2, special issue «Dialogue Interpreting», Manchester, St. Jerome Publishing.

Mesa, A.-M. (1997): L'interprète culturel: un professionel apprécié. Étude sur les services d'interprétation: le point de vue des clients, des intervenants et des interprètes, Montréal, Régie régionale de la santé et des services sociaux de Montréal-Centre.

Morris, R. (1995): “The Moral Dilemmas of Court Interpreting," The Translator, 1-1, pp. 25-46.

Moser-Mercer, B. (1996): "Quality in interpreting: Some methodological issues," The Interpreters' Newsletter, 7, pp. 43-55.

Niska, H., coord. (1999): "Quality Issues in Remote Interpreting," Anovar/Anosar estudios de traducción e interpretación (A. Álvarez Lugrís and A. Fernández Ocampo, eds), Vigo, Universidade de Vigo, vol. I, pp. 109-121.

PöсннаскеR, F. (1994): Simultandolmetschen als komplexes Handeln, Tübingen, Gunter Narr.

- (2000): "The Community Interpreter's Task: Self-Perception and Provider Views," The Critical Link 2: Interpreters in the Community (R.P. Roberts, S.E. Carr, D. Abraham and A. Dufour, eds), Amsterdam and Philadelphia, John Benjamins.

Rehbein, J. (1985): "Ein ungleiches Paar-Verfahren des Sprachmittelns in der medizinischen Beratung," Interkulturelle Kommunikation (J. Rehbein, Hrsg.), Tübingen, Gunter Narr, pp. 420-448.

Roвson, C. (1993): Real World Research, Oxford, Blackwell.

Roy, C. (1993): "A Sociolinguistic Analysis of the Interpreter's Role in Simultaneous Talk in Interpreted Interaction," Multilingua, 12-4, pp. 341-363.

Shlesinger, M. (1994): "Intonation in the Production and Perception of Simultaneous Interpretation," Bridging the Gap: Empirical Research in Simultaneous Interpretation (S. LAMBERT and B. Moser-Mercer, eds), Amsterdam and Philadelphia, John Benjamins, pp. 225-236.

- (1997): "Quality in Simultaneous Interpreting," Conference Interpreting: Currents Trends in Research (Y. Gambier, D. Gile and C. Taylor, eds), Amsterdam and Philadelphia, John Benjamins, pp. 123-131.

Strong, M. and S. Fritsch-Rudser (1992): "The Subjective Assessment of Sign Language Interpreters," Sign Language Interpreters and Interpreting (D. CoKeLY, ed.), Burtonsville (MD), Linstok Press, pp. 1-14. 
Tommola, J. and J. Lindholm (1995): "Experimental Research on Interpreting: Which Dependent Variable?," Topics in Interpreting Research (J. TommoLA, ed.), pp. 121-133, Turku, University of Turku Centre for Translation and Interpreting.

VIezzI, M. (1996): Aspetti della Qualità in Interpretazione, Trieste, SSLMIT.

Vuorikoski, A.-R. (1993): "Simultaneous Interpretation-User Experience and Expectation," The Vital Link. Proceedings of the XIIIth World Congress of FIT (C. Picken, ed.), London, Institute of Translation and Interpreting, vol. 1, pp. 317-327.

WADENSJö, C. (1998): Interpreting as Interaction, London and New York, Longman.

YAGI, Sane M. (1999): “Computational Discourse Analysis for Interpretation,” Meta, 44-2, pp. 268-279. 